\title{
Trajetória política, reforma administrativa e ações para a juventude: o caso da Divisão para Assuntos da Juventude em Blumenau ${ }^{1}$
}

\author{
Pablo Filipe Quintani²
}

- Enviado em 25/02/2016

- Aprovado em 30/05/2016

\section{RESUMO}

Este artigo fala sobre o processo de institucionalização de um espaço, dentro da esfera municipal, para a execução de políticas para juventude. Este espaço é a Divisão para Assuntos da Juventude (DAJ) da cidade de Blumenau/SC. Esta análise buscou reconstruir como se deu esse processo de institucionalização revelando os diferentes aspectos de ordem política, eventos históricos e atores envolvidos na criação da DAJ.

Palavras-chave: Juventude. Política públicas. Blumenau.

\section{INTRODUÇÃO}

Este artigo fala sobre o processo de institucionalização de um espaço, dentro da esfera municipal, para a execução de políticas para juventude. Este espaço é a Divisão para Assuntos da Juventude (DAJ) da cidade de Blumenau/SC. Esta análise buscou reconstruir como se deu esse processo de institucionalização revelando os diferentes aspectos de ordem política, eventos históricos e atores envolvidos na criação da DAJ. O artigo está divido em duas partes: a primeira busca contextualizar os aspectos políticos e sociais implicados no tema; o segundo faz uma descrição do processo de institucionalização. Ao final, esperasse que seja compreendido como três fatores entrelaçados convergem para a criação da DAJ. O primeiro fator é a emergência de um ator político na cena local, Vilson Kleinübing, respondendo ao anseio de uma elite empresarial tradicional. O segundo fator diz respeito a organização coletiva da base militante da Juventude Democrática (JD), centrada em Sergio Hoffmann. O terceiro fator corresponde a uma série de mudanças institucionais com origem nas reformas administrativas do Estado no final da década de 1980 relacionadas

1 Dissertação de mestrado defendida em 28/04/2015 no Programa de Pós Graduação em Sociologia da UFPR sob a orientação da Professora Doutora Maria Tarcisa Silva Bega. Versão integral disponível na Biblioteca Digital da UFPR http://www.portal.ufpr.br/teses_acervo.html.

2 Mestre em Sociologia pela Universidade Federal do Paraná. Endereço eletrônico: pfquintani@gmail.com. 
também ao processo de redemocratização e emergência de novos atores coletivos, entre os quais, aqueles substanciados pela juventude.

\section{BLUMENAU E JUVENTUDE}

A cidade de Blumenau está localizada na mesorregião do Vale do Itajaí, no estado de Santa Catarina. Com uma população estimada em 334 mil habitantes e com uma área de unidade territorial estimada em $518,497 \mathrm{~km} 2^{3}$ é considerada a terceira maior cidade do estado. Seu Índice de Desenvolvimento Humano é de $0,806^{4}$, colocando a cidade entre as melhores posições, em nível nacional, de qualidade de vida.

Atualmente a cidade é conhecida pela sua tradicional festa da cerveja, a Oktoberfest, mas também tem destaque na produção da indústria têxtil e no setor de serviços, em especial o polo da informática. Os desastres sócio ambientais também são uma marca da região. A cidade vem sofrendo ao longo da sua história pelas frequentes enchentes e deslizamentos de terra em sua geografia acidentada, repleta de morros e vegetação de mata atlântica. $\mathrm{O}$ desenvolvimento da cidade se confunde com a história do rio que atravessa a cidade, o Rio Itajaí-Açu. Pois foi através desse que os primeiros colonizadores alemães, liderados por Dr. Hermann Bruno Otto Blumenau, alcançaram a margem onde hoje é localizada a região central da cidade. Como conta Machado (2008, p. 14)

A cidade de Blumenau foi, a princípio, idealizada como uma colônia particular com fins de assentamento de colonos imigrantes, vindos inicialmente da ainda não formada Alemanha a partir de 1850, em um vale localizado no nordeste da Província de Santa Catarina, no sul do Império Brasileiro.

Em relação a população de jovens de Blumenau destaca-se que é possível perceber que essa parcela da população vem diminuindo de proporção desde a década de $1990^{5}$. A tabela a seguir ilustra esse ponto.

3 IBGE, 2014.

4 IBGE, 2010.

5 Dados obtidos a partir de Blumenau (1990). 
PROPORÇÃO DE JOVENS NA FAIXA ETÁRIA ENTRE 15 E 29 ANOS EM RELAÇÃO A POPULAÇÃO

TOTAL DAS RESPECTIVAS AMOSTRAS: BRASIL, SANTA CATARINA E BLUMENAU.

\begin{tabular}{cccc}
\hline & 1991 & 2000 & 2010 \\
\hline BRASIL & $28,07 \%$ & $28,23 \%$ & $26,91 \%$ \\
SANTA CATARINA & $28,96 \%$ & $27,18 \%$ & $26,84 \%$ \\
\hline BLUMENAU & $29,83 \%$ & $27,84 \%$ & $27,46 \%$ \\
\hline
\end{tabular}

FONTE: IBGE, 2010. Elaborado pelo autor.

Proporcionalmente a década de 1980 foi favorável em relação a participação dos jovens na cidade por conta de duas variáveis: a primeira é o contexto de redemocratização e fim do regime militar, aonde estavam sendo colocadas novas bandeiras que clamavam por mudanças na sociedade brasileira. Dava-se a emergência e organização de novos grupos, mulheres, jovens, negros, movimento ambiental, que ansiavam por um projeto político que contemplasse as reivindicações de uma sociedade plural; a segunda variável diz respeito ao próprio volume demográfico dos jovens em Blumenau, como ilustra a tabela acima.

A juventude blumenauense também se organizou em torno de algumas questões que surgiram na pauta política dos movimentos sociais: a mobilização pelo ensino superior público, questão da preservação ambiental, grupo de artistas, em especial o teatro, etc. Em síntese, é possível falar em uma matização entre três principais grupos de jovens:

- Aqueles reunidos em torno dos partidos políticos, quer sejam de um espectro mais conservador ou mais progressista, podendo ser citados o Partido dos Trabalhadore (PT), Partido do Movimento Democrático Brasileiro (PMDB) e Partido Democrático Social (PDS). Aonde atuavam a militância jovem, quer buscando transformações mais "radicais" aliados a um pensamento "socialista", quer buscando reformas sociais de caráter mais conservador. A principal forma de atuação se dava pela via institucional da política partidária;

- Grupos de artistas que se reuniam sem uma pauta específica, mas que movimentavam a cultura local. Sua atuação se concentrava em criar uma rede de contatos e de trabalho, produzindo arte na cidade. Não tendo uma estratégia incisiva na política local;

- Grupos formados por estudantes, aonde estão distribuídos aqueles que militam especificamente em torno de questões relacionados as condições do ensino superior e da educação pública; e aqueles estudantes que trazem a pauta dos estudos acadêmicos, fazendo penetrar na sociedade reivindicações 
específicas em torno de temáticas como: meio ambiente; novas formas de participação política; questões de gênero, movimento negro, etc.

Pode-se então perceber que os jovens em Blumenau, apesar de fragmentários, correspondiam a uma parcela importante da sociedade e buscavam através da organização coletiva espaço e reconhecimento. Contudo, essa fragmentação não contribuía para um projeto único que pudesse colocar a juventude na agenda política do governo local.

\section{POLÍTICAS PÚBLICAS PARA JUVENTUDE}

A juventude, ou juventudes ${ }^{6}$, é um ator coletivo de grande relevo quando analisado o seu papel ao longo de diferentes processos de transformação social em determinados momentos da história. Vários trabalhos já se detiveram nesse tema ${ }^{7}$. Como destaca Eisenstad (1976) e Mannheim (1967; 1982) a juventude possui um grande potencial para mudanças, dada a forma como está inserida na sociedade moderna. Poderíamos destacar, na história recente, a participação dos jovens nos movimentos pelas Diretas, Caras Pintadas, Passe Livre, etc., apenas para ficarmos com exemplos brasileiros. O que mostra que nos momentos de conflito a juventude desempenha um papel de destaque.

Dessa forma, como estes momentos de conflito também revelam a difícil relação entre Estado e sociedade, a juventude aparece como um ator dotado de interesses particulares. Mesmo que presente em diferentes frentes de disputa - meio ambiente, moradia, transporte público, educação, etc. - dada a sua parcela representativa e sua organização coletiva pode-se perceber que os jovens abrem uma janela dentro da agenda de problemas políticos na nossa sociedade. A resolução desse problemas é o foco da ação política. Uma definição de políticas públicas nos mostra essa associação.

Políticas públicas são decisões que envolvem questões de ordem pública com abrangência ampla e que visam à satisfação do interesse de uma coletividade. Podem também ser compreendidas como estratégias de atuação pública, estruturadas por meio de um processo decisório composto de variáveis complexas que impactam na realidade para promovê-las, mas tal encargo vem sendo cada vez mais compartilhado com a sociedade civil por meio do desenvolvimento de variados mecanismos de participação decisória. (AMABILE, 2012, p. 390)

6 Considerando aqui por juventudes a grande diversidade de jovens e suas diferentes condições de classe, posição política, características culturais e étnicas.

7 Ver para isso Groppo (2000). 
Ou como pretende Rua (1998, p. 731 - 732)

proponho o entendimento das políticas públicas como conjuntos de decisões e ações destinadas à resolução de problemas políticos. Essas decisões e ações envolvem atividade política, compreendida esta como o conjunto de procedimentos formais e informais que expressam relações de poder e se destinam à resolução pacifica de conflitos a bens públicos. (...) as políticas públicas se destinam a solucionar problemas políticos, que são as demandas que logram ser incluídas na agenda governamental

Pode-se então afirmar que uma variável importante a ser considerada quando se discute o surgimento de uma política pública é a dimensão conflituosa de disputa por recursos em uma dada sociedade. Assim, ao discutir sobre a concepção de policy arena, Klaus Frey (2000, p. 223) destaca que essa se refere "aos processos de conflito e de consenso dentro das diversas áreas de política, as quais podem ser distinguidas de acordo com o seu caráter distributivo, redistributivo, regulatório ou constitutivo." Considerando também que "as reações e expectativas das pessoas afetadas por medidas políticas têm um efeito antecipativo para o processo político de decisão e de implementação"8. Sendo assim, em uma sociedade democrática, o jovem entra no diálogo político tanto no momento de pleito eleitoral, como durante o exercício do próprio governo.

\section{BLUMENAU E VILSON KLEINÜBING}

Para compreender a criação da DAJ é de fundamental importância reter o papel desempenhado pelo ator político Vilson Pedro Kleinübing 9 . Foi durante o período que esteve a frente do executivo municipal de Blumenau em que a DAJ foi criada e entregue nas mãos de Sérgio Hoffmann. Kleinübing não é natural de Blumenau, mas foi nesta cidade que dá um importante passo na sua carreira política. Em menos de 10 anos,

8 Segundo o autor: "1. Políticas distributivas são caracterizadas por um baixo grau de conflito dos processos políticos, visto que políticas de caráter distributivo só aparecem distribuir vantagens e não acarretam custos - pelo menos diretamente percebíveis - para outros grupos (...) Em geral, políticas distributivas beneficiam um grande número de destinatários, todavia em escala relativamente pequena; potenciais opositores costumam ser incluídos na distribuição de serviços e benefícios.; 2. Políticas redistributivas, ao contrário, são orientadas para o conflito. (...) O processo político que visa a uma redistribuição costuma ser polarizado e repleto de conflitos. (...) 3. Políticas regulatórias trabalham com ordens e proibições, decretos e portarias. Os efeitos referentes aos custos e benefícios não sãodetermináveis de antemão; dependem da configuração concreta das políticas. (...) 4. Políticas constitutivas (...) determinam as regras do jogo em com isso a estrutura dos processos e conflitos políticos, isto é, as condições gerais as quais vêm sendo negociadas a configuração específica das políticas.” (FREY, 2000, p. 223 - 224)

9 Ver a biografia escrita por Pereira (2001). 
Vilson Kleinübing, passa de prefeito de Blumenau, para governador de Santa Catarina e Senador, carreira apenas interrompida pelo seu falecimento devido a um câncer.

Nascido em Montenegro/RS (1944), filho de Waldemar Kleinübing e Carmelina Pontin Kleinübing, casado com Vera Maria Karam Kleinübing, com quem teve 3 filhos: João Paulo Karam Kleinübing ${ }^{10}$, Eduardo Karam Kleinübing e Diogo Karam Kleinübing. Mudou-se, ainda criança, com a família para a cidade de Videira no meio oeste catarinense. Fez os estudos primários no Colégio Imaculada Conceição (1951 - 1959). Ainda em Videira trabalhou como auxiliar de escritório (1958 - 1959) no Banco Contábil Ltda. Cursou o primeiro e segundo ano do Colegial Científico na capital Florianópolis, no Colégio Catarinense. O terceiro ano foi completado em Porto Alegre no Colégio Anchieta (1960 - 1962). Ainda no Rio Grande do Sul, cursou a Universidade Federal do Rio Grande do Sul (UFRGS), aonde completou o curso de Engenheiro Mecânico (1963 - 1968) e foi membro do Diretório Acadêmico da Escola de Engenharia. Nos últimos anos de sua graduação trabalhou no cargo de Chefe de Planejamento e Controle da Produção da Ipesul Ltda (1967 - 1968).

Mudou-se novamente para Florianópolis aonde exerceu o cargo de Engenheiro Assistente de Gerência da filial INEAL - Engenharia e Arquitetura S/A, em 1969. Nesse momento, cursa uma PósGraduação em Engenharia Econômica na Universidade Federal de Santa Catarina (UFSC) em 1970. Vai então ingressar como docente na Universidade do Estado de Santa Catarina, lecionando a disciplina de Processamento de Dados, na Escola Superior de Administração e Gerência (ESAG) no período de 1970 até 1978. Também em 1970, inicia sua carreira dentro das Centrais Elétricas de Santa Catarina (CELESC), aonde é selecionado, inicialmente, para Análises de Sistemas (1970), passando para Assessor do Diretor Administrativo (1972), Chefe do Departamento de Processamento de Dados (1973) e finalmente Diretor de Distribuição (1979). Enquanto morava em Florianópolis, foi Presidente e Vice-Presidente da Sociedade Balneário Daniela (Associação de Moradores da localidade) de 1974 até 1976, espaço que lhe conferiu contato com alguns nomes da política da ilha de Florianópolis, como Esperidião e Angela Amin ${ }^{11}$. Também participou e projetou a Reforma Administrativa daAssociação Comercial e Industrial da cidade de Joinville.

A sua ascensão política esta ligada a sua origem e as pessoas com quem conseguiu estabelecer relações de confiança. Seu pai, Waldemar Kleinübing, foi prefeito de Videira, pequena cidade do extremo oeste catarinense, e Udenista ferrenho. O pai de Vilson Kleinübing obteve ajuda na construção de uma estação de tratamento de água através do então vice-governador Jorge Konder Bornhausen. Este encontro, ocorrido em 1968, marca o primeiro contato que mais tarde será a chave para o vinculo entre Vilson

10 João Paulo Kleinübing, assim como o pai, foi prefeito de Blumenau e também trabalhou na Rádio Clube e atribui à sua participação na emissora grande parte da popularidade que o levou a eleger-se em 2004 como o mais jovem prefeito da cidade.

11 Que naquele momento possuíam uma estreita relação com Jorge Bornhausen. Tanto é que em 1978 Kleinübing apoia e dá suporte a candidatura de Amin para prefeito de Florianópolis. 
Kleinübing e Jorge Bornhausen. Kleinübing através da sua formação como engenheiro vai atuar dentro de secretarias e órgão públicos, estreitando ainda mais sua relação com nomes importante da cena política local e conferindo-lhe um capital político suficiente para em 1982 lançar-se candidato a deputado federal pelo Partido Democrático Social (PDS). Apesar de eleito, não exerce o cargo pois é chamado, pelo então governador Esperidião Amin (1983 - 1986), a assumir a Secretaria da Agricultura e Abastecimento de SC.

No final da década de 1980 ocorre uma mudança nos rumos das alianças políticas de SC. Jorge Bornhausen vai fundar o Partido da Frente Liberal (PFL), Amin, até então seu aliado político, dá as costas para Bornhausen e permanece no PDS. Kleinübing, permanece no PDS com a esperança de ser o sucessor de Amin para o governo do estado, mas suas expectativas são frustradas levando este a uma maior aproximação com Bornhausen. Neste momento, Kleinübing sai como nome do PFL para o governo de SC, perde mas recebe expressivo número de votos, em especial na cidade de Blumenau. Surge então a ideia e oportunidade de lançar-se candidato a prefeito de Blumenau nas eleições de 1988.

Em Blumenau, apesar da cisão entre PFL e PDS que havia ocorrido em nível estadual, PFL, PDS e PL aglutinaram-se na coligação União Por Blumenau. Kleinübing chama para a vice-prefeitura o candidato derrotado em 1982, Victor Fernando Sasse (PDS). O produto dessa união é uma esmagadora vitória na cidade. Deve-se destacar também outro fator importante. Kleinübing consegue esta vitória graças as influências e patrocínio do empresariado local, devido a sua estreita relação com Jorge Konder Bornhausen, e a sua estratégia de utilizar o radio local para tornar seu nome público e reconhecido entre a população. Nesse sentido, podemos concluir que a estreita relação de Kleinübing com a população jovem da cidade está relacionada com a sua tentativa de construir uma base eleitoral forte e diversificada.

\section{REFORMA ADMINISTRATIVA DO ESTADO}

A reforma da administração pública foi um processo pelo qual se deu a modernização da estrutura burocrática do Estado. Suas consequências, em relação ao objeto dessa pesquisa, estão relacionadas a modificação da Estrutura Administrativa do Poder Executivo no Município de Blumenau. A criação da DAJ está diretamente relacionado a este reordenamento dos órgãos na gestão do governo local. No Brasil, nos interessa em especial as mudanças decorrentes da Constituição de 1988, em seu artigo no 37, que dispõe sobre a Administração Pública: "A administração pública direta, indireta ou fundacional, de qualquer dos Poderes da União, dos Estados, do Distrito Federal e dos Municípios obedecerá aos princípios de legalidade, impessoalidade, moralidade, publicidade". Significando um avanço na tentativa de eliminar as relações de clientelismo e patrimonialismo presentes na cultura política do Brasil e enraizadas na sociedade brasileira. 
A reforma administrativa de Blumenau, no bojo das mudanças orientadas pela Constituição Federal de 1988, teve início em 5 de abril de 1989 com o plano de ação para a Constituinte Municipal estabelecido pela Resolução de no 166 de 2 de março de 1989. A Lei Orgânica Municipal foi então promulgada em sessão solene no dia 5 de abril de 1990. Em tese, a proposta era adequar a situação local a fim de promover a descentralização das competências garantindo a atuação em cooperação com a União e o Estado, permitindo o equilíbrio, desenvolvimento e o bem-estar da comunidade local, regional e nacional, preservados os interesses municipais.

Em 5 de maio de 1989, antes mesmo da promulgação da Lei Orgânica de Blumenau, é instituída a nova Estrutura Administrativa do Poder Executivo do Município, revogando a Lei no 1915/73. Com essa nova estrutura administra dá-se novas responsabilidades para setores municipais e são criados outros, reordenando a hierarquia administrativa. As mudanças são significativas, tanto no que tange atribuições como no tamanho e complexidade da própria estrutura burocrática.

Ao que se refere o nosso órgão de interesse, ou seja, aquele que tenha como responsabilidade a juventude, no período anterior a 1989 não havia um setor que fosse específico para essa função. Em 1973, o órgão responsável pelo atendimento e garantia do Bem-Estar era a Secretaria de Saúde e Bem Estar Social. Entre suas atribuições estão: atuar como órgão normativo em saúde pública e assistência social; manter convênios com a União e o Estado para a promoção de campanhas e programas de saúde; promover o atendimento de pessoas carentes de recursos; assessorar no estabelecimento de convênios com instituições de assistência social e fiscalizar a sua execução. O órgão é então dividido em dois departamentos: de Saúde e o de Bem Estar Social. Indiretamente, esta secretaria oferece serviços que possam atender a população jovem, porém não direcionados especialmente a ela.

Outra secretaria que acumula funções que passam pela questão da juventude é a Secretaria de Educação e Cultura, dividida entre os Departamentos de Educação e Cultura.

Depois de 1989, a nova estrutura administrativa do executivo vai estabelecer como subordinados ao Gabinete do Prefeito os seguintes departamentos: de Ação Comunitária, de Expediente e o de Relações Públicas. Subordinado ao Departamento de Ação Comunitária ficou a Divisão para Assuntos da Juventude. Através da lei complementar no 1, de 04 de junho de 1990 é instituído o regime jurídico único para os servidores públicos do município, das autarquias e das fundações públicas instituídas e mantidas pelo município, estabelecendo ainda as diretrizes gerais para sua implantação e atividades. Apesar desses avanços de caráter legal, a DAJ acaba se tornando um órgão com baixíssima autonomia e sem dotação orçamentária. Resultando em um espaço ocupado por um cargo comissionado que executa uma política de caráter personalista sem conseguir enraizar-se como política de Estado, ou seja, sem continuidade após as trocas de governo. 


\section{A CRIAÇÃO DA DIVISÃO PARA ASSUNTOS DA JUVENTUDE}

A DAJ, na cidade de Blumenau, foi uma criação da gestão do governo municipal do prefeito Vilson Kleinübing ${ }^{12}$. A DAJ foi um órgão criado com o objetivo de planejar, gerir e executar a política de juventude no município ${ }^{13}$. Estava subordinada ao Departamento de Ação Comunitária, que por sua vez estava subordinado ao Gabinete do Prefeito. A DAJ foi composta, no momento de sua criação, apenas por um pessoa, Sergio Hofmann ${ }^{14}$, que assume então o cargo de Chefe da DAJ. Quando o vice-prefeito, Victor Fernando Sasse, assume a prefeitura em 1991 altera novamente a estrutura administrativa do município ${ }^{15}$, subordinando então a Divisão para Assuntos da Juventude ao Departamento de Bem- Estar Social, e subordinando esse à Secretaria Municipal de Ação Comunitária. EM 1889 o pleito eleitoral ao governo municipal dividia duas lideranças dentro da possível coligação Partido Democratico Social (PDS) e Partido da Frente Liberal (PFL). De um lado Wilson Rogério Wan- Dall ${ }^{16}$ pelo PDS e do outro Vilson Kleinübing pelo PFL. Durante a campanha eleitoral Vilson Kleinubing foi ganhando destaque na cena local. Era considerado um "político muito competente, trazia um ar de integridade e capacidade técnica". Kleinübing conseguiu exercer uma forte atração carismática na população blumenauense. A então vice presidente da Juventude Democrata (JD) sinalizou para Sergio Hoffmann que seria importante para a JD que Kleinübing fosse conversar com o grupo sobre as suas propostas para a Juventude da cidade. Ela então organizou o encontrou que aconteceu na sede da Juventude Democrata.

Nós tínhamos ali na rua Amadeu da Luz 78 , nós tínhamos em cima de um prédio, a sede do partido e ai uma vez por mês tínhamos a reunião e eu presidi a juventude do PSD. (Hoffmann, 2014)

12 Kleinübing esteve à frente da prefeitura de Blumenau entre 1989 e 1990, ano em que se lança candidato ao cargo de governador do estado, elegendo-se e assumindo a função em 1991. Em seu lugar assume seu vice Victor Fernando Sasse.

13 Lei $n^{\circ} 3567$ de 5 de maio de 1989, dispõe sobre a estrutura administrativa do poder executivo do Município de Blumenau.

14 Que até o momento era o presidente da Juventude Democrata.

15 Lei Complementar no 4 de 5 de novembro de 1990

16 Wilson Wan-Dall já era Deputado Estadual, cargo que continuou a exercer depois de não ter concorrido à Prefeitura de Blumenau em 1988. 
O encontro tinha como objetivos apresentar as propostas da JD para um dos possíveis candidatos à Prefeitura de Blumenau. Segundo Hoffmann, o grupo já possuía uma série de projetos que poderiam ser implantados pelo chefe do executivo. Inclusive a ideia da criação de um órgão para atender a população jovem. A reunião também buscava declarar, se assim fosse decidido pelo grupo, apoio político ao candidato.

Ela (vice presidente da juventude do PDS) havia conversado com o Kleinübing e achou ele muito receptivo (...) A vice presidente da juventude percebia que Kleinübing considerava a juventude da cidade de Blumenau muito interessante. Pois quando ele (Kleinübing) vai na rua, todo mundo abraça o cara, quer bater foto com ele. (Hoffmann, 2014)

Hoffmann recebe a notícia um pouco a contragosto, afinal o nome de Wan-Dall era o mais cotado para o pleito na cidade pelo seu grupo político. Mesmo assim, Kleinübing vai até a sede da JD, é recebido e ouvido por todos. Ao final da fala de Kleinübing, Hoffmann expõe o seu ponto de vista.

Olha, eu sou luterano e me lembro das teses que lá o Martinho Lutero defendeu, e eu vou defender não as teses todas dele, mas eu vou defender uma só. De que para a juventude, para o idoso, para a nossa cidade a gente só precisa de uma coisa: o homem certo no lugar certo. Nós temos alguém, tem um candidato que está trabalhando, mas ele não tem o meu apoio, porque eu acho que o cara não é o cara certo. Então, o que pudermos fazer para elegê-lo, vou the dizer, da minha parte não teria problema algum. Agora, como o senhor viu, eu sou realmente democrático, não forço barra nenhuma, o que eles decidirem eu vou apoiar, até porque nós temos um candidato. Alguém que se colocou a disposição como candidato, o qual eu não concordo muito. Mas não é a minha opinião, é a opinião do pessoal que vai decidir. Cara, dai ele sentou novamente. E ele falou mais uma hora. Ai foi legal. Resumo da ópera, eu falei para ele: Nada que foi colocado aqui eu vou entender como promessa política, porque eu quero acreditar que o senhor tem realmente boas intenções e que estas intenções vão virar depois prática e a gente vai estar de acordo com a sua candidatura na medida em que o senhor assumir realmente esse compromisso. Não queremos promessa, queremos ação. (...) Ele ficou encantado com o que ele viu e ouviu. Acabou então criando o cargo. Resumo da ópera, quando ele ganhou, um dia me toca o telefone lá em casa e ele me convida para assumir. Ele disse: Olha, vamos estruturar a Juventude. Ai um dia fui lá conversar com ele. Ele me pergunta o que a gente ia fazer. Eu disse: Não sei. O que podemos fazer é perguntar para a Juventude. Ai, a ideia que eu dei a ele, e ele muito receptivo, foi de fazermos um encontro com a juventude, para debater com eles, e eu propus de fazermos na câmara de vereadores. E eu comecei a me articular com os grupos. (Hoffmann, 2014)

Como mostra a entrevista com Sergio Hoffmann, foi durante essa reunião que ficou decido a criação da DAJ. O projeto inicial era de autoria da JD. Contudo, somente após a vitória de Kleinübing é que foi articulada a criação da DAJ. Em sua concepção original, Hoffmann afirma que o cargo de chefe da DAJ 
deveria ser transitório. Para Hoffmann, a DAJ deveria ser criada apenas para articular a criação do Conselho da Juventude, que depois de estruturada poderia funcionar de forma independente. Ou seja, se fosse da preferência dos jovens, a DAJ poderia funcionar como a executora das decisões tomadas pelo Conselho, inclusive poderiam ser realizadas eleições para escolha do chefe da divisão. Na concepção inicial essa seria a forma de atuação do chefe da divisão.

Kleinübing foi receptivo e até achou genial a ideia, porque é coisa simples. (...) É um cargo que é bancado pelo município mas ele até quebra um pouco a ideia do cargo de confiança porque o chefe da divisão até poderia ser eleito, ali, pelo jovens, através do conselho de juventude que seria criado. (Hoffmann, 2014)

Entre algumas ações feitas pelas DAJ, podemos citar da primeira gestão: uma reunião realizada na Câmara de Vereadores aonde compareceram 200 grupos de jovens ${ }^{17}$; também foram realizadas reuniões com grupos de jovens buscando a efetivação de um Conselho da Juventude ${ }^{18}$; o gestor da DAJ, Sérgio Hoffmann, também tinha como projeto a criação de um Albergue da Juventude ${ }^{19}$, este seria construído com apoio da Federação Brasileira dos Albergues da Juventude que era o Órgão Diretor da política de alberguismo do Brasil. Segundo outro gestor da DAJ, Fabrício Wolff, que assumiu o cargo antes do término do mandato do primeiro gestor ${ }^{20}$, durante a primeira gestão, além dos encontros e reuniões, foram realizados alguns torneios de futebol, que acabaram em pancadaria. Em 10/07/1989, Sergio Hoffmann é exonerado do cargo para assumir a Coordenação do Serviço Administrativo da Secretaria de Desenvolvimento Econômico. Em seu lugar, no dia 01/08/1989, é nomeada Iracy Terezinha Dallabona.

Sobre a gestão de Iracy não foi possível encontrar qualquer registro de atividade, relatório ou notícia de jornal que permitisse conhecer suas ações. Em entrevistas com Sérgio Hoffmann, que a antecedeu e com Fabrício Wolff que a procedeu, não foi possível conhecer nenhuma ação da gestão Iracy. Ambos desconheciam o que aconteceu durante o período.

A Gestão da DAJ de Fabrício Wolff é lembrada principalmente pelos eventos artísticos que contaram com bandas do cenário nacional. O Gestor, que vinha da área de publicidade e jornalismo, conseguiu através

17 Informação divulgada pelo Jornal de Santa Catarina no dia 10 de março de 1992. Através de entrevista, o então gestor da DAJ confirmou que a Câmara de Vereadores ficou lotada, mas não soube informar a real quantidade de grupos e pessoas que participaram.

18 Apesar das reuniões terem sido confirmadas, o conselho nunca chegou a ser criado.

19 O albergue também não chegou a sair do papel, apesar da documentação ter sido criada e inclusive o terreno ter sido formalmente solicitado frente a prefeitura.

20 Que acabou se afastando para assumir outro cargo, na Divisão responsável pelas Associações de Moradores. 
de várias parcerias, entre público e privado, arrecadar verbas e tocar projetos como: o Rock na Rua, que tinha como atração bandas locais tocando em vários bairros da cidade; a Gincana Cidade de Blumenau, criada em 1993 que teve um crescimento vertiginoso e acabou servindo de modelo para outras cidades, inclusive no plano nacional; e em 1995 ocorreu o maior evento de Rock que a cidade já havia recebido, o Skol Rock Blumenau, que teve como grande atração a banda Mamonas Assassinas.Fabrício comenta da sua facilidade em conseguir estabelecer contatos na região, em especial com os meios de comunicação local. "Eu falava com o pessoal da Atlântida e para qualquer coisa que a Assessoria fizesse eu ganhava comercial de graça lá. (Fabrício Wolff, 2013)

Quando assume o cargo, Wolff lembra que a Divisão não tinha recurso financeiros. Tendo então de estabelecer alguns contatos para conseguir montar uma pequena equipe, contando com mais dois comissionados e dois concursados do departamento de Ação Comunitária, e ganhar uma sala para o trabalho. Até hoje a atuação do Fabrício Wolff na DAJ ${ }^{21}$ é lembrada como a mais exitosa, inclusive rendeu ao gestor uma homenagem, pela Câmara de Vereadores, por serviços prestados. Fabrício Wolff assume o cargo no governo de Renato Vianna (PMDB) e é mantido no cargo como comissionado, não sendo um funcionário de carreira da prefeitura de Blumenau. É interessante ressaltar que Fabrício é um nome que permanece trabalhando na prefeitura, atualmente com cargo na Assessoria de Imprensa, independente da mudança do governo municipal, com a exceção do período PT (1997 - 2003).

Segundo Fabrício Wolff, dois projetos que ele ansiava não foram concluídos durante sua gestão: a criação de um programa de primeiro emprego, por falta de apoio das secretarias e departamentos; e as olimpíadas da juventude.

Eu queria muito ter feito uma olimpíada inter-bairros da juventude, unindo associações de moradores. Através das associações de moradores organizar uma olimpíada esportiva para jovens. Até porque, o esporte é bom para tudo. E politicamente também seria bom porque você envolve as associações de moradores. Geralmente eivadas de interesses políticos, dentro delas, de futuros candidatos, enfim, para aglutinar, para somar. (Wolff, 2013)

Durante os dois governos de Décio Nery de Lima pelo Partido dos Trabalhadores estive a frente da Divisão de Assuntos da Juventude um grupo formado na militância do partido. Pelas entrevistas foi possível constatar que a DAJ, até aquele momento se encontrava abandonada, após a gestão Fabrcio Wolff "nada realmente aconteceu". Não foi possível conseguir nenhum registro da atuação da DAJ até a entrada de Pedro

21 Que durante este momento, por iniciativa do próprio gestor, foi renomeada para Assessoria para Assuntos da Juventude. 
Nogueira, no ano de 2000. Sobre a DAJ, Fabrício Wolff comenta a respeito do período posterior a sua gestão.

Depois disso trocou muito, no período do Décio, trocaram 7 ou 8 vezes em 4 anos. Teve uma galera ai, então a coisa meio que se perdeu. E nestes últimos anos do João Paulo ${ }^{22}$ (filho de Vilson Kleinübing) também teve, em 8 anos, mais uns 4 diferentes assessores, no mínimo. O que é ruim, porque você não consegue uma continuidade no trabalho. (Wolff, 2013)

Quando assumiu, Pedro revela que a DAJ estava praticamente desativada, não possuía dotação orçamentária própria. Durante todo o período pesquisado foi possível perceber isso, pois toda ação realizada pela DAJ precisou buscar ou apoio em entidades privadas, através de patrocínio, ou coordenava alguma ação conjuntamente com outro departamento ou secretaria que tivesse orçamento próprio. Dessa forma, talvez seja mais correto considerar que a DAJ sempre funcionou como uma espécie de Assessoria, fazendo a articulação entre Juventude e Prefeitura de Blumenau. Os chefes da Divisão deveriam utilizar da sua influência e contatos para estabelecer parcerias que permitissem alguma ação voltada para a juventude. É elucidativa a opinião de Fabrício sobre a DAJ. "A assessoria da juventude tem de apoiar, mas a galera é que tem que fazer. O governo tem que ajudar. Dava para fazer um Rock na rua, sempre. Mas a sociedade tem que se organizar." (Fabrício Wolff, 2013)

Ainda segundo Pedro, quando assumiu a DAJ em 2000, a equipe foi composta por uma secretária e outro cargo comissionado, sem função específica, mas que fora escolhido pelo próprio chefe da divisão para "ajudar nas atividades e organizar o local". A nomeação de Pedro se deu por uma indicação setorial que "debatia as políticas para e com as juventudes" este grupo vinha de dentro da militância jovem do PT. Pedro, até aquele momento, era militante do PT, da Pastoral da Juventude da Igreja Católica e do movimento estudantil.

Minha função era de assessor para assuntos da juventude. Quando assumo o departamento, minha função era organizar o departamento e colocar o tema juventude em debate nas questões de políticas públicas (...) Meu trabalho era de motivação da pequena equipe e ao mesmo tempo mostrar que a juventude precisava de um espaço de elaboração. E que a juventude não era só o debate de educação e emprego. (Nogueira, 2014) 
A percepção do chefe da divisão era de que até aquele momento não havia um debate sobre a questão da juventude, não havia um projeto ou ideias claras sobre o que deveria ser feito. Faltavam relatórios e material que permitissem subsidiar a discussão. Quando o tema juventude aparecia na pauta da agenda política, se limitava às discussões sobre emprego e educação, isso era o consenso, mesmo dentro dos grupos e movimentos locais. A proposta do Pedro Nogueira era justamente iniciar esse debate que transcendia o emprego e a educação.

Debate de lazer, debate de cultura e outras coisas não existiam. Havia também a concepção de que o departamento era somente eleitoral e que era somente algo para tratar de uma única atividade: a gincana Cidade de Blumenau e fazer um evento de música. Essa era a concepção tanto da prefeitura, quanto da sociedade. Encontro o departamento somente com uma equipe reduzida e sem local fixo de trabalho, também sem autonomia administrativa, política e financeira." (Nogueira, 2014)

Depois de assumir o cargo, as primeiras iniciativas foram: Iniciar o debate sobre as políticas públicas para e com a juventude, sendo que até aquele momento, segundo sua percepção, não havia nada discutido pelas gestões anteriores; O nome passou a ser Assessoria de Assuntos da Juventude, pois segundo Pedro, fazia mais sentido e ia ao encontro da real atuação do órgão, dada as suas limitações orçamentárias e legais; Através de pressão frente às secretarias e departamentos já existentes, tentou-se forçar a criação de um espaço próprio com equipamento e equipe capaz de atuar de forma mais profissional, considerando as demandas locais da juventude.

Iniciada as atividades, as primeiras discussões tiveram como tema central a própria noção de juventude. Ou seja, um período de estudo entre a equipe para alinhar seu projeto com as discussões de cunho mais acadêmico, assim como da necessidade em criar um Conselho da Juventude. De fato, realmente o projeto foi encaminhado, votado e aprovado, mas nunca saiu do papel. Ao procurarem novos subsídios para "tocar o projeto" começaram a estabelecer outros contados e "participar" do movimento em nível nacional.

Participamos do debate nacional sobre a Concepção de Políticas Públicas para e com a(s) Juventude(s). Neste debate tivemos a coragem de realizar o 2o Congresso da Juventude - o 1o Congresso da Juventude foi de um dia e teve uma palestra sobre drogas e estas coisas, tema bem clichê mesmo. Na ocasião do encontro tinha que levar uma Lata de Leite. Também foi realizado outro encontro de 3 dias. Neste tivemos debates, oficinas, encaminhamentos, e o produto final destes debates levamos, na época, um relatório final para Brasília. Aonde aconteceu a 1a Conferência Nacional da Juventude. Estava começando a discussão do Estatuto da Juventude e o debate de políticas públicas para o segmento. Realizamos Conferência Livre de Juventude, que na época era permitido pelo regimento da Conferência Nacional. Realizamos o 1o Encontro de Gestores de Juventude do Sul do país. Tivemos participantes do Rio grande 
do Sul, Paraná e Santa Catarina juntamente com nosso Congresso, a abertura foi em conjunto com a participação, na época, do Instituto de juventude, Deputado Vignatti, Deputado Reginaldo Lopes e Helena Abramo, que é uma especialistas no debate de juventude, e no nosso Congresso teve a participação de vários especialistas do país que debatiam o tema. (Nogueira, 2014)

Depois desse momento, que permitiu dar forma ao projeto para a juventude em Blumenau, foram realizadas as seguintes ações:

- Debate sobre o primeiro emprego, colocando em prática o Programa de Primeiro Emprego e regulação através da Lei 5686 de 15 de agosto de 2001 que foi aprovada só depois de muita discussão 91 na Câmara de Vereadores e com as Secretarias da prefeitura;

- Organizaram debates com os estudantes secundaristas, levando a reativação de grêmios estudantis e a União Municipal dos Estudantes;

- Realizaram discussões através de palestras e encontros com o Movimento Estudantil. Dessa forma participaram da criação do Festival Universitário da Canção de Blumenau - FUCCA em conjunto com o Diretório Central dos estudantes da Universidade Regional de Blumenau - FURB

- Organizaram palestras e oficinas, entre elas uma de grafite, com Internados do Centro de Internação de Adolescentes e Jovens de Blumenau;

- Realizaram festivais de musica que levaram a gravação de um CD com bandas locais;

- Reformularam a Gincana Cidade de Blumenau, com o intuito de que ela tivesse maior penetração nos bairros periféricos da cidade. Como relata o entrevistado: "Criamos a Juventude nos Bairros que era levar os Gincaneiros para conhecer a cidade que muitas vezes eles não conheciam, o lado "podre" da cidade;

- Ajudaram a criar a Liga dos Gincaneiros, que permitiu maior autonomia do grupo, tendo organização e direção própria;

- Participaram e ajudaram a organizar atividades com as Igrejas locais.

Ao comentar sobre o período, Pedro faz um resumo do que, até aquele momento, era o debate sobre Juventude nos espaços institucionais da cidade. Segundo o entrevistado, a Prefeitura se limitava aos órgãos tradicionais de ação, a Secretaria de Educação de Cultura, não havendo um projeto de ação específico para atender os jovens. Algumas ONG's tinham algumas ideais, mais no campo da assistência social (filantropia e voluntariado) para dependentes químicos. A CNBB também participava à sua maneira e os jovens da militância política tinham seus grupos, servindo tanto para formas novos quadros de base e levantar as demandas dos seus integrantes como para "porta de entrada" na carreira política. A Divisão para Assuntos da 
Juventude em Blumenau ficava restrita mesmo aos eventos culturais que já foram citados. Não havia um entendimento do papel do Estado na formulação e implementação de políticas públicas de juventude. Em uma fala elucidativa, o entrevistado resume qual, segundo a sua percepção, precisava ser a sua iniciativa “Tínhamos que fazer o debate para dentro do Governo!’(Pedro Nogueira, 2014).

A equipe de Pedro Nogueira em 2003 já era composta por mais integrantes. Faziam parte do grupo Eliomar Russi que era comissionado, mas não tinha função específica; Josué que era um servidor administrativo designado para auxiliar a Assessoria; Alexandre Fagundes e Alexandre Lopes que eram estagiários e faziam pequenos serviços e Martin Stabel Garrote, que é historiador e se dedicava principalmente ao Programa Primeiro Emprego, Martin também ajudou a elaborar um relatório sobre as atividades, mas não foi possível encontrar este documento.

Das administrações pós-governo PT não foi possível encontrar documentos sobre as atividades. A Assessoria mudou de nome, foi então nomeada Gerência de Assuntos para Juventude, continuando subordinada ao Gabinete do Prefeito. A mudança está relacionada alteração da Estrutura Administrativa do Poder Executivo realizada quando da troca do governo municipal. Devemos compreender essa mudança na nomenclatura como uma alteração formal. Ou seja, na prática o que realmente muda são apenas "formalidades" sendo que o conteúdo do documento pouco condiz com a atuação do gestor. Pode-se dizer que, durante os Governos DEM (2004 - 2011) e PSDB (2012 - atual), o órgão serviu como base política do governo, os eventos culturais ficaram a cargo da Fundação Cultural de Blumenau, as ações na área de Assistência Social se limitaram aos seus órgãos específicos e o programa Primeiro Emprego não mais é uma atribuição da Gerência de Assuntos da Juventude.

Foram realizados uma série de encontros com o objetivo de criar o Conselho da Juventude. Para tal tarefa foi então organizado um grupo "fechado" 93 de trabalho, que nas primeiras reuniões contou com a presença de alguns jovens interessados - artistas independentes e participantes do movimento VamuSiuní os encaminhamentos resultaram na realização de um Encontro da Juventude de Blumenau, realizada na Igreja Matriz, no centro da cidade, mas que, apesar da expectativa de concentrar mais de 5 mil jovens, contou apenas com a presença dos próprios organizadores e alguns lideres locais de entidades como: Rottary Club, Estudantes Secundaristas, Cisne Negro - movimento negro, militância jovem do PSDB, clube de oratória da cidade, e cerca de 30 pessoas que não representavam nenhuma entidade de classe ou grupo da cidade.

Em 2015 o Gestor Fred Manke foi substituído, para assumir um cargo comissionado dentro do Gabinete do Prefeito, e assumiu João Paulo Taumaturgo, que foi um membro desse grupo de trabalho que realizou o Encontro em Blumenau, sendo também integrante da militância jovem do PSDB. Limitando-se a realizar reuniões com lideranças políticas do município e do Estado e trabalhar como "assessor de imprensa" não oficial da gestão Napoleão Bernardes (PSDB) 
É possível concluir que a Divisão, e depois Gerência, de Assuntos para Juventude em Blumenau passou por 4 fases importantes. A primeira foi a sua criação, onde temos o nome de Sérgio Hoffmann, líder da Juventude do PSD até 1989, que assume o cargo após estabelecer um contato próximo com o então prefeito eleito Vilson Kleinübing. Apesar das várias ideias que traz para o projeto de criação da Divisão, praticamente nada foi efetivado além das reuniões que ocorreram na Câmara de Vereadores da cidade. Sergio Hoffmann permanece muito pouco tempo no cargo. Após sua substituição, a Divisão aparece novamente com alguma iniciativa durante o período em que está a sua frente o Fabrício Wolff. Nesta segunda fase o então profissional da área jornalistica, consegue realizar eventos culturais de grande destaque pela mídia local. Entre os eventos o de maior público e publicidade foi o Skol Rock, realizado na prainha em 1994. Após a saída de Fabrício Wolff, a divisão volta a ganhar algum destaque quando já está no governo de Décio Lima (PT), de 2000 até 2003. Nesta terceira fase a DAJ chefiada por Pedro Nogueira participou de alguns eventos a nível estadual e nacional que permitiram à equipe aperfeiçoar um pouco sua forma de Ação. Sua participação estendeu-se ao programa Primeiro Emprego, foi produzido 1 (um) relatório sobre a juventude em Blumenau. Com a saída do governo PT e eleição de João Paulo Klleinübing (PFL) no primeiro mandato e no segundo pelo DEM) foi iniciado um ciclo de nova inércia das atividades da Divisão, representando então sua quarta fase. Em 2009 é alterado a nomenclatura da Divisão para Gerência de Assuntos da Juventude, através da Lei Complementar no 505 que estabelece nova organização da estrutura administrativa. Em 2013, é eleito prefeito Napoleão Bernardes ${ }^{23}$ (PSDB) que chama para o cargo de chefia da Gerência de Assuntos da Juventude Fred Manke ${ }^{24}$. Fred Manke permanece no cargo até 2015, quando assume João Paulo Taumaturgo. Nesse período apesar das reuniões de trabalho que levaram a um novo projeto para criação do Conselho da Juventude, não é possível apontar alguma iniciativa realizada pelo órgão.

\section{CONSIDERAÇÕES FINAIS}

Ao abordar o processo de institucionalização da DAJ em Blumenau, percebe-se que em se tratando de um projeto político para a juventude o Estado ainda esbarra em fortes contradições. Estas dizem respeito ao forte personalismo adotado pelos atores envolvidos resultando na incapacidade, ao menos a nível local, de enraizar uma política pública para juventude. Em Blumenau, este aspecto, ficou evidente quando a criação da DAJ mostra-se como uma necessidade identificada por Vilson Kleinübing para garantir uma base política entre os jovens. E quando Sergio Hoffmann, apesar do esforço para democratizar e discutir o projeto, não

23 Professor universitário da FURB e ex-vereador eleito em 2008.

24 Até então membro do diretório do Centro Acadêmico de Estudantes de Direito da Universidade Regional de Blumenau, o Diretório Acadêmico Clóvis Beviláqua - DACLOBE. 
consegue efetivar as bases para uma política para a juventude na cidade. Fica evidente também, essa condição, quando Fabrício Wolff só consegue materializar ações mediante apoio de entidades privadas e que buscassem alternativas de lazer focadas para uma parcela muito reduzida de jovens. As discussões em torno do trabalho, educação, moradia, segurança, etc., acabam pulverizadas e não aparecem na agenda da DAJ.

A criação da DAJ, e seu processo de institucionalização, também revela como uma análise focada em um ponto especifico, de uma cidade, de determinados atores e de um processo político, é importante para caracterizar os fundamentos que acabam sendo reproduzidos em outros contextos. Permitindo uma reflexão sobre aspectos mais gerais, como cultura política, instituições públicas e discursos, que devem ser considerados para a compreensão de casos particulares.

\section{REFERÊNCIAS}

AMABILE, Antonio. O conceito de políticas públicas. In: CASTRO, Carmem Lúcia Freitas de; GONTIJO, Cynthia Rúbia Braga; AMABILI, Antônio Eduardo de Noronha (Org.). Dicionário de Políticas Públicas. Barbacena: Eduemg, 2012. 480 p.

BLUMENAU. Relatório de atividades 1990. Blumenau, 1990.

Lei Orgânica do Município de Blumenau, 29 de março de 1990.

Lei Ordinária no 1915, de 12 de março de 1973. Dispõe sobre a estrutura administrativa da prefeitura municipal de Blumenau e dá outras providências.

Lei Complementar no 1, de 04 de junho de 1990. Institui o regime jurídico único para os servidores públicos do município, das autarquias e das fundações públicas instituídas e mantidas pelo município, estabelece diretrizes gerais para sua implantação e dá outras providências.

Lei Complementar no 3, de 30 de outubro de 1990. Institui o plano de carreira para os servidores públicos do poder executivo, estabelece diretrizes gerais para sua implantação.

. Lei Ordinária no 1818, de 16 de dezembro de 1971. Cria conselho municipal de obras sociais e dá outras providências.

BRASIL. Constituição da República Federativa do Brasil de 1988. Disponível em: <http://www.planalto.gov.br/ccivil_03/constituicao/constituicao.ht m> Acessado em 10/12/2014.

EISENSTAD, Shmuel Noah. De geração a geração. São Paulo: Perspectiva, 1976

FREY, Klaus. Políticas públicas: um debate conceitual e reflexões referentes à prática da análise de políticas públicas no Brasil. Planejamento e Políticas Públicas, Brasília, n. 21, jun. 2000.

GROPPO, Luí. Juventude: ensaios sobre a Sociologia e história das juventudes modernas. Rio de Janeiro: Ed. Difel, 2000. 
HOFFMANN, Sergio. Entrevista concedida em 05/08/2014.

MACHADO, Ricardo. Entre o público e o privado: gestão do espaço e dos indivíduos em Blumenau (1850 - 1920). Blumenau: Edifurb, 2008.

MANNHEIM, Karl. O problema das gerações. In: FORACCHI, Marialice. Karl Mannheim: sociologia. São Paulo: Ática, 1982.

Karl. Diagnóstico do nosso tempo. Rio de Janeiro: J. Zahar, 1967.

NOGUEIRA, Pedro. Entrevista concedida em 08/04/2014.

PEREIRA, Moacir. Kleinübing: uma trajetória de sucesso. 2. ed. Florianópolis: Insular, 2001. 232 p.

RUA, Maria das Graças. As políticas públicas e a juventude dos anos 90. In: Comissão Nacional de População e Desenvolvimento. Jovens acontecendo na trilha das políticas públicas. Brasília: CNPD, 1998

WOLFF, Fabrício. Entrevista concedida em 26/07/2013.

\section{Trajectory political, administrative reform and actions for youth: the case of the Division for Youth Affairs in Blumenau}

\section{Abstract}

This paper is about the institutionalization process of a space within the municipal level, for policy implementation to youth. This space is the Division for Youth Issues (DAJ) of the city of Blumenau/SC. This analysis sought to reconstruct how was this process of institutionalization revealing different aspects of political, historical events and actors involved in creating the DAJ.

Key-words: Youth. Public policies. Blumenau. 